\title{
High serum cortisol level is associated with increased risk of delirium after coronary artery bypass graft surgery: a prospective cohort study
}

\author{
Dong-Liang Mu', Dong-Xin Wang ${ }^{1 *}$, Li-Huan Li ${ }^{2}$, Guo-Jin Shan', Jun Li ${ }^{1}$, Qin-Jun Yu², Chun-Xia Shi
}

See related commentary by Kazmierski and Kloszewska, http://ccforum.com/content/15/1/102

\begin{abstract}
Introduction: The pathophysiology of postoperative delirium remains poorly understood. The purpose of this study was to examine the relationship between serum cortisol level and occurrence of early postoperative delirium in patients undergoing coronary artery bypass graft (CABG) surgery.

Methods: A total of 243 patients undergoing elective CABG surgery were enrolled. Patients were examined twice daily during the first five postoperative days and postoperative delirium was diagnosed by using the Confusion Assessment Method for the Intensive Care Unit (CAM-ICU). Blood samples were obtained between 7 a.m. and 8 a. $\mathrm{m}$. on the first postoperative day and serum cortisol concentrations were then measured. Multivariate logistic regression analyses were performed to identify risk factors of postoperative delirium.

Results: Postoperative delirium occurred in 50.6\% (123 of 243) of patients. High serum cortisol level was significantly associated with increased risk of postoperative delirium (OR 3.091, 95\% Cl 1.763-5.418, $P<0.001)$. Other independent risk factors of postoperative delirium included increasing age (OR 1.111, 95\% Cl 1.065-1.159, $P<$ 0.001 ), history of diabetes mellitus ( $\mathrm{OR} 1.905,95 \% \mathrm{Cl} 1.001-3.622, P=0.049)$, prolonged duration of surgery (OR $1.360,95 \% \mathrm{Cl} 1.010-1.831, P=0.043$ ), and occurrence of complications within the first day after surgery (OR 2.485, $95 \% \mathrm{Cl} 1.184-5.214, P=0.016)$. Patients who developed postoperative delirium had a higher incidence of postoperative complications and a prolonged duration of postoperative ICU and hospital stay.

Conclusions: Delirium was a common complication after CABG surgery. High serum cortisol level was associated with increased risk of postoperative delirium. Patients who developed delirium had outcomes worse than those who did not.
\end{abstract}

\section{Introduction}

Delirium is a common complication after cardiac surgery. According to the Diagnostic and Statistical Manual of Mental Disorders, Fourth Edition (DSM-IV), delirium is a transient mental syndrome characterized by (a) disturbance of consciousness with a reduced ability to focus, sustain, or shift attention; (b) change in cognition (such as memory deficit, disorientation, or language disturbance) or development of a perceptual disturbance that is not better accounted for by a

\footnotetext{
* Correspondence: wangdongxin@hotmail.com

'Department of Anesthesiology and Surgical Intensive Care, Peking University First Hospital, No. 8 Xishiku Street, Beijing 100034, PR China Full list of author information is available at the end of the article
}

preexisting, established, or evolving dementia; and (c) disturbance developing over a short period of time (usually hours to days) and tending to fluctuate during the course of the day [1]. The reported incidences of delirium after cardiac surgery varied from 3\% to $72 \%$ [2-5], and the occurrence of postoperative delirium is associated with multiple adverse effects, such as selfextubation, prolonged hospital stay, increased healthcare costs, and high mortality rate [6-11].

Despite the numerous studies, the pathophysiology of delirium remains poorly understood $[12,13]$. As a universal phenomenon, delirium is frequently identified after major complicated surgery (including cardiac and vascular surgery) but rarely noted after minor

\section{C) Biomed Central}


ambulatory surgery (such as cataract surgery) [5,14-16]. These findings suggest that the stress response induced by surgical stimuli might play an important role in the pathogenesis of postoperative delirium.

Cortisol is one of the most important stress hormones in humans. Its secretion is proportional and positively correlated to the severity of surgical stimuli $[17,18]$. A reciprocal control, the hypothalamic-pituitary-adrenal axis, exists between the brain and glucocorticoid hormones. Under stressful conditions, the brain promotes adrenocortical function via hypothalamic corticotrophinreleasing hormone. On the other hand, glucocorticoids act at specific receptors in the hypothalamus, thus producing negative feedback mechanisms.

It has long been observed that high levels of circulating glucocorticoids might have harmful effects on the brain and cause psychiatric symptoms [19-21]. This is because there are glucocorticoid receptors in the hippocampus and frontal lobe, the regions that are closely associated with cognition. The effects of glucocorticoids on cognition follow an inverted U-shape dose response relationship; that is, memory is impaired by sustained glucocorticoid levels that are too low or too high but is improved by proportionate glucocorticoid level [22].

However, the relationship between circulating cortisol level and the occurrence of postoperative delirium has not been fully demonstrated. A recent study by Shi and colleagues [23] found that elevated serum cortisol level was associated with increased incidence of postoperative delirium in critically ill patients after noncardiac surgery. We suppose that the occurrence of postoperative delirium in patients undergoing cardiac surgery is also related to stress response and, thus, the elevated circulating cortisol level. The purpose of this study was to examine the association between serum cortisol level and occurrence of early postoperative delirium in patients undergoing coronary artery bypass graft (CABG) surgery.

\section{Materials and methods}

The study protocol was approved by the clinical research ethics committees of Peking University First Hospital and Beijing Fuwai Hospital. All patients gave written informed consent.

\section{Patients}

This was a prospective cohort study. The inclusion criteria were consecutive adult patients who were referred to Beijing Fuwai Hospital for elective CABG surgery from March 2008 to July 2008. The exclusion criteria were as follows: (a) previous cardiothoracic surgery, (b) history of schizophrenia, (c) history of adrenal gland disease, (d) history of glucocorticoid therapy for more than 7 consecutive days within 1 year, (e) preoperative left ventricular ejection fraction of less than 25\% (echocardiography, Simpson's method), and (f) concomitant surgery other than CABG, such as valvular replacement.

\section{Anesthesia, surgery, and postoperative care}

Patients were premedicated with midazolam $(7.5 \mathrm{mg}$ by mouth) and morphine (10 mg intramuscularly). Anesthesia was induced with fentanyl ( 5 to $10 \mu \mathrm{g} / \mathrm{kg}$ ), etomidate $(0.2$ to $0.3 \mathrm{mg} / \mathrm{kg})$, and rocuronium $(0.6 \mathrm{mg} / \mathrm{kg})$. Anesthesia was maintained with midazolam $(0.1$ to $0.2 \mathrm{mg} / \mathrm{kg})$, fentanyl (20 to $30 \mu \mathrm{g} / \mathrm{kg}$ ), isoflurane ( $0.5 \%$ to $1 \%$ ), and propofol (2.4 to $4.0 \mathrm{mg} / \mathrm{kg}$ per hour during cardiopulmonary bypass). Muscle relaxation was maintained with supplemental doses of vencuronium. Intraoperative monitoring included 5-lead electrocardiogram, radial arterial pressure, central venous pressure, pulse oxygen saturation, end-tidal expiratory carbon dioxide, nasopharyngeal temperature, bladder temperature, and urine output. A pulmonary artery catheter was inserted when necessary.

The type of surgery (on-pump or off-pump surgery) and the number of bypass grafts were determined by the surgeons. All patients underwent CABG surgery through a median sternotomy. Aortic palpation was used to detect atherosclerosis and, if present, to select an appropriate site for cannulation and clamping. For patients undergoing off-pump surgery, distal anastomoses were performed with the help of an Octopus tissue stabilizer (Medtronic, Inc., Minneapolis, MN, USA). Proximal anastomoses were then fashioned onto the aorta by means of a single side-clamp. Nasopharyngeal temperature was maintained above $35^{\circ} \mathrm{C}$, and systolic blood pressure was kept at $80 \mathrm{~mm} \mathrm{Hg}$ or greater throughout the procedure.

For patients undergoing on-pump surgery, cardiopulmonary bypass was established with a Stöckert S3 roller pump (Stöckert Instrumente GmbH, Munich, Germany), a membrane oxygenator (Maxima Forte; Medtronic, Inc.), and a $40-\mu \mathrm{m}$ arterial blood filter (Dideco, Mirandola, Italy). Moderate hypothermia $\left(32^{\circ} \mathrm{C}\right)$ and $\alpha$-stat acid-base management were used. Perfusion pressure was kept at 60 to $80 \mathrm{~mm} \mathrm{Hg}$, and a pump flow was maintained between 2 to $2.4 \mathrm{~L} / \mathrm{min}$ per $\mathrm{m}^{2}$. After all distal anastomoses were completed, the aortic cross-clamp was removed, and proximal anastomoses were then performed by means of a single side-clamp on the aorta.

After surgery, all patients were transferred to the intensive care unit (ICU) intubated and were placed on mechanical ventilation. Propofol and morphine were routinely administered for sedation and analgesia. Midazolam was administered as required. Extubation and ICU discharge were decided by attending intensivists. Hospital discharge was decided by the attending surgeon. Patients were followed up until 28 days after 
surgery. Definitions of postoperative complications are shown in Table 1.

\section{Measurement of serum cortisol level}

Blood samples were obtained between 7 and 8 a.m. on the first postoperative day. BD tubes (Becton, Dickinson and Company, Franklin Lakes, NJ, USA) were used throughout the study. Prior to the assay, the samples were kept refrigerated for no longer than 12 hours at $4^{\circ} \mathrm{C}$. Serum cortisol concentration was measured with a solid-phase, competitive chemiluminescent enzyme immunoassay in a calibrated IMMULITE 1000 analyzer (Diagnostic Products Corporation, Los Angeles, CA, USA). The intra-assay and interassay coefficients of variation at various concentrations were less than $5.6 \%$ and less than $8.2 \%$, respectively. The normal range is 138 to $690 \mathrm{nmol} / \mathrm{L}$ in the laboratory where measurements were performed.

\section{Delirium assessment}

Delirium assessment was performed in two steps. First, level of sedation (level of arousal) was assessed by means of the Richmond Agitation Sedation Scale (RASS) [24,25]. This is a 10-point scale with four levels of anxiety or agitation $(+1$ restless to +4 combative), one level representing an alert and calm state (0), and five levels of sedation $(-5=$ nonarousable to $-1=$ drowsy). If the patient was deeply sedated or was unarousable ( -4 or -5 on the RASS), assessment was stopped and then was repeated later. If RASS was above $-4(-3$ through +4$)$, assessment was continued to the next step. Second, delirium was diagnosed by means of the Confusion Assessment Method for the Intensive Care Unit (CAM-ICU) [26,27]. This is an instrument designed to diagnose delirium in nonverbal, critically ill patients. It indicates four features of delirium: (a) acute onset of mental status changes or a fluctuating course, (b) inattention, (c) disorganized thinking, and (d) altered level of consciousness. To meet the diagnostic definition of delirium, a patient must display both (a) and (b) and either (c) or (d).

Prior to the study, the physician performing the assessment of delirium (D-LM) was trained by a psychiatrist to use CAM-ICU. Definition and examples of delirium features were explained and discussed. For the purpose of training and standardization, eligible patients were randomly selected and each patient was independently evaluated by the investigator (according to CAM-ICU) and the psychiatrist (according to DSM-IV) during the same observational period. The process continued until agreement for the diagnosis of delirium reached $100 \%$. During the study phase, patients were assessed for delirium twice daily (from 6 to 8 a.m. and from 6 to 8 p.m.). For each patient, delirium assessment was performed until the fifth postoperative day or the disappearance of delirious symptoms for two consecutive days. Study personnel who assessed delirium were blinded to the treatment details and the serum cortisol results.

\section{Statistical analysis}

Continuous variables are presented as mean \pm standard deviation (SD) or median (interquartile range). Data were compared with the use of the independent samples $t$ test or the Mann-Whitney $U$ test. Categorical variables are presented as number of patients (percentage). Data were compared with the use of the chi-square test or the Fisher exact test. The effect of serum cortisol level on the occurrence of postoperative delirium was assessed with the use of multivariate logistic regression analyses. Initially, baseline and perioperative variables were evaluated for univariate association with postoperative delirium. Variables that were significant in univariate analyses $(P<0.10)$ were included in a multivariate logistic regression model to determine the risk-adjusted predictors of delirium. Two-sided $P$ values of less than 0.05 were regarded as significant. All statistical analyses were performed with the SPSS statistical package, version 14.0 (SPSS Inc., Chicago, IL, USA).

\section{Results}

Two hundred seventy-six patients underwent elective CABG surgery during the study period, and 258 matched the criteria of selection. Among the eligible

Table 1 Definitions of postoperative complications

\begin{tabular}{ll}
\hline Complications & Requirements for acceptance \\
\hline $\begin{array}{l}\text { Cardiac insufficiency } \\
\text { Arrhythmia }\end{array}$ & $\begin{array}{l}\text { Requirement of inotropic support for more than } 24 \text { hours or intra-aortic balloon pump support or both } \\
\text { Myocardial }\end{array}$ \\
$\begin{array}{l}\text { Increase of troponin T concentration above the hospital laboratory's myocardial infarction threshold and either new Q waves } \\
\text { infarction }\end{array}$ & Requirement of mechanical ventilation for more than 24 hours \\
Respiratory & Appearance of persisted new focal neurologic deficit and confirmed by neurologic imaging study \\
Stroke & Two or more of systemic inflammatory response syndrome criteria, with known or suspected evidence of infection \\
Sepsis & Confirmed by chest x-ray film and necessitated aspiration or surgical drainage \\
Pleural effusion & Requirement of reoperation to stop bleeding \\
Surgical bleeding &
\end{tabular}


patients, 243 gave written consent and were enrolled in this study (Figure 1). The perioperative variables of all enrolled patients are listed in Tables 2 and 3.

One hundred twenty-three patients developed delirium after surgery, resulting in an overall postoperative delirium rate of $50.6 \%$ (123 of 243). Among patients who developed delirium, the median (interquartile range) time of occurrence of the initial delirious symptom was 1 ( 1 to 2 ) day after surgery. In $97.6 \%$ of the delirious cases (120 of 123), the initial symptom occurred within the first 3 days after surgery (Figure 2). The median duration of postoperative delirium (that is, the duration between the initial symptom and the last symptom) was 2 ( 1 to 4 ) days.

Four patients died within 28 days after surgery, resulting in an overall 28 -day mortality rate of $1.6 \%$. Two of them died of intractable ventricular fibrillation on the 1 st and 3rd postoperative day, respectively. Because of unarousable sedation or coma, these two patients were not assessed for delirium. The other two patients died of circulatory failure and multiple organ failure on the 10th and 26th postoperative day, respectively. Both of them experienced early postoperative delirium.

Variables that were significant in univariate analyses $(P<0.10)$ are listed in Table 4 . Patients with high serum cortisol level had a significantly higher incidence of postoperative delirium $(P<0.001)$ (Figure 3$)$. After the multicollinearity was tested, two variables were excluded from further multivariate logistic regression analysis because of high correlation with others (duration of anesthesia versus duration of surgery, Pearson correlation coefficient $=0.967, P<0.001$; serum cortisol concentration versus serum cortisol level, Spearman correlation coefficient $=0.867, P<0.001)$. There was only a weak correlation between serum cortisol concentration

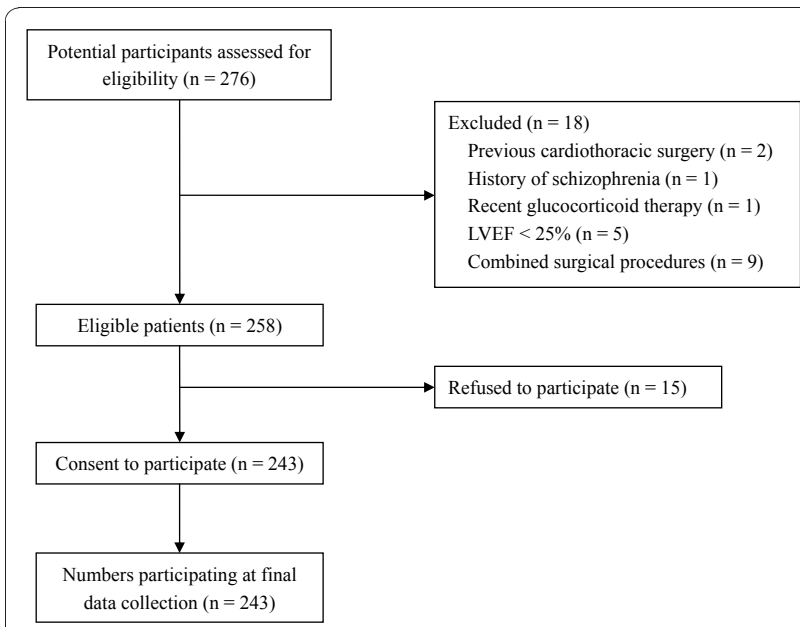

Figure 1 Flow diagram of the study. LVEF, left ventricular ejection fraction. and APACHE II (Acute Physiology and Chronic Health Evaluation II) score on arrival in the ICU (Kendall correlation coefficient $=0.122, P=0.008)$. No significant correlation existed between serum cortisol concentration and duration of surgery (Pearson correlation coefficient = -0.003, $P=0.963)$, use of cardiopulmonary bypass (Kendall correlation coefficient $=-0.018, P=0.735$ ), or duration of mechanical ventilation in the ICU (Pearson correlation coefficient $=-0.018, P=0.790)$. So the above four variables were included in the multivariate analysis. On the other hand, since most of the delirious cases were diagnosed on the first day after surgery, we included only the complications that occurred before or during the first postoperative day in the multivariate analysis.

As a result, 11 variables were consecutively subjected to a stepwise logistic regression analysis. Five were identified as independent predictors of postoperative delirium (Table 4). Of particular note was that high serum cortisol level was associated with significantly increased risk of postoperative delirium in this risk-adjusted analysis (odds ratio [OR] 3.091, 95\% confidence interval [CI] 1.763 to $5.418 ; P<0.001$ ). Replacement of serum cortisol level with serum cortisol concentration in nanomoles per liter did not change the results, and high serum cortisol concentration remained an independent risk factor of postoperative delirium (OR 1.002, 95\% CI 1.000 to 1.003; $P=0.006)$.

Comparison between patients with or without postoperative delirium showed that the former group had significantly more occurrences of postoperative complications, prolonged duration of ICU stay, and prolonged duration of postoperative hospital stay. The former group also tended to have greater medical expense during hospitalization (Tables 3 and 5).

\section{Discussion}

In the present study, we demonstrated that, in patients undergoing CABG surgery, elevated serum cortisol level on the first day after surgery was highly correlated with increased risk of postoperative delirium. Other independent risk factors included increasing age, history of diabetes mellitus, longer duration of surgery, and occurrence of complications within the first day after surgery. Our study also confirmed that outcomes were worse in patients who developed postoperative delirium: they had a higher incidence of postoperative complications, prolonged durations of postoperative ICU and hospital stay, and a tendency to greater medical expense during hospitalization.

The reported incidences of postoperative delirium varied from $3 \%$ to $72 \%$ after all types of cardiac surgery and from $3 \%$ to $50 \%$ after CABG surgery [2-6,28-32]. A recent study by Rudolph and colleagues [33] reported a 
Table 2 Preoperative variables

\begin{tabular}{|c|c|c|c|c|}
\hline Variable & $\begin{array}{l}\text { All enrolled patients } \\
\qquad(n=243)\end{array}$ & $\begin{array}{l}\text { Non-delirious patients } \\
\qquad(n=120)\end{array}$ & $\begin{array}{l}\text { Delirious patients } \\
\quad(n=123)\end{array}$ & $P$ value \\
\hline Age, years & $61.0 \pm 8.3$ & $58.3 \pm 8.0$ & $63.6 \pm 7.7$ & $<0.001$ \\
\hline Body mass index, $\mathrm{kg} / \mathrm{m}^{2}$ & $26.1 \pm 3.5$ & $26.2 \pm 3.9$ & $26.0 \pm 3.0$ & 0.643 \\
\hline Education, years & $10.4 \pm 4.4$ & $10.4 \pm 4.3$ & $10.4 \pm 4.4$ & 0.992 \\
\hline Female gender & $43(17.7 \%)$ & $21(17.5 \%)$ & $22(17.9 \%)$ & 0.937 \\
\hline \multicolumn{5}{|l|}{ Previous medical history } \\
\hline Hypertension & $161(66.3 \%)$ & $75(62.5 \%)$ & $86(69.9 \%)$ & 0.221 \\
\hline Previous myocardial infarction ${ }^{\mathrm{a}}$ & $114(46.9 \%)$ & 55 (45.8\%) & 59 (48.0\%) & 0.739 \\
\hline Diabetes mellitus & 89 (36.6\%) & $36(30.0 \%)$ & $53(43.1 \%)$ & 0.034 \\
\hline Hyperlipidemia & $96(39.5 \%)$ & 47 (39.2\%) & $49(39.8 \%)$ & 0.915 \\
\hline Arrhythmia & $58(23.9 \%)$ & $26(21.7 \%)$ & $32(26.0 \%)$ & 0.426 \\
\hline Stroke & $31(12.8 \%)$ & $11(9.2 \%)$ & $20(16.3 \%)$ & 0.097 \\
\hline COPD & $6(2.5 \%)$ & $1(0.8 \%)$ & $5(4.1 \%)$ & 0.213 \\
\hline Renal dysfunction ${ }^{\mathrm{b}}$ & $9(3.7 \%)$ & $4(3.3 \%)$ & $5(4.1 \%)$ & 1.000 \\
\hline Chronic smoking ${ }^{c}$ & 79 (32.5\%) & $40(33.3 \%)$ & $39(31.7 \%)$ & 0.787 \\
\hline Alcoholism ${ }^{d}$ & $34(14.0 \%)$ & $21(17.5 \%)$ & $13(10.6 \%)$ & 0.119 \\
\hline Habitual benzodiazepine use & $23(9.5 \%)$ & $12(10.0 \%)$ & $11(8.9 \%)$ & 0.778 \\
\hline Previous general anesthesia & $17(7.0 \%)$ & $9(7.5 \%)$ & $8(6.5 \%)$ & 0.761 \\
\hline Preoperative LVEF, percentage ${ }^{e}$ & $58.0 \pm 9.6$ & $59.4 \pm 8.4$ & $56.7 \pm 10.5$ & 0.024 \\
\hline Preoperative CCS class & & & & 0.736 \\
\hline 1 & $53(21.8 \%)$ & $24(20.0 \%)$ & $29(23.6 \%)$ & \\
\hline$\|$ & $126(51.9 \%)$ & $63(52.5 \%)$ & $63(51.2 \%)$ & \\
\hline III & $53(21.8 \%)$ & $26(21.7 \%)$ & $27(22.0 \%)$ & \\
\hline IV & $11(4.5 \%)$ & $7(5.8 \%)$ & $4(3.3 \%)$ & \\
\hline Preoperative NYHA functional class & & & & 0.089 \\
\hline 1 & $77(31.7 \%)$ & $45(37.5 \%)$ & $32(26.0 \%)$ & \\
\hline$\|$ & $131(53.9 \%)$ & $62(51.7 \%)$ & $69(56.1 \%)$ & \\
\hline III & $35(14.4 \%)$ & $13(10.8 \%)$ & $22(17.9 \%)$ & \\
\hline Preoperative EuroSCORE score & $2.6 \pm 2.1$ & $2.0 \pm 1.8$ & $3.2 \pm 2.1$ & $<0.001$ \\
\hline
\end{tabular}

Data are presented as mean \pm standard deviation or number of patients (percentage). ${ }^{a}$ Myocardial infarction of more than 1 month before surgery. ${ }^{b}$ Serum creatinine of greater than $177 \mu \mathrm{mol} / \mathrm{L}$. ${ }^{\mathrm{c} S}$ moking of more than 20 cigarettes per day within 1 month. ${ }^{\mathrm{d}}$ Consumption of an equivalent of $150 \mathrm{~mL}$ of alcohol per week. ${ }^{~}$ Results of echocardiography (Simpson's method). CCS, Canadian Cardiovascular Association; COPD, chronic obstructive pulmonary disease; EuroSCORE, European System for Cardiac Operative Risk Evaluation; LVEF, left ventricular ejection fraction; NYHA, New York Heart Association.

rate of $52 \%$. The reasons that produce this great variation include difference in patient population (such as age, severity of illness and type of procedure), sensitivity of the screening instrument, and local medical practice (such as routine practice and critical care environment). Although, in our study, patients were relatively young and underwent low-risk closed-chamber surgery [34,35], the incidence is higher than some previously reported ones. This is perhaps because we assessed delirium twice daily for five consecutive days after surgery and thus detected more delirious cases. Even though it was not found to be a significant risk factor, the frequent use of anticholinergics during surgery in our study is another possible reason for this higher incidence.

The cause of delirium is typically multifactorial [12]. Delirium occurs as a result of a complex interrelationship between predisposing and precipitating factors $[12,36]$. Numerous studies have been performed to find out the risk factors for developing postoperative delirium, and there is substantial heterogeneity in the findings [3-6,28-32]. Increasing age is a universally identified risk factor of delirium $[2,12,36]$, suggesting that the naturally aged brain might be the basis of the occurrence of delirium. A history of diabetes mellitus is associated with increased incidence of almost all kinds of cerebral complications after cardiac surgery, including stroke [37], cognitive dysfunction [38], and delirium $[39,40]$. This is perhaps because long-standing diabetes mellitus increases the prevalence of intracerebral atherosclerotic disease [41]. On the other hand, a long duration of surgery indicates a more complex procedure and the occurrence of postoperative complications means a more eventful recovery, and both long duration of surgery and postoperative complications have also been found to be associated with the occurrence of delirium $[3,42,43]$. 
Table 3 Perioperative variables

\begin{tabular}{|c|c|c|c|c|}
\hline Variable & $\begin{array}{l}\text { All enrolled patients } \\
\qquad(n=243)\end{array}$ & $\begin{array}{l}\text { Non-delirious patients } \\
\qquad(n=120)\end{array}$ & $\begin{array}{l}\text { Delirious patients } \\
\qquad(n=123)\end{array}$ & $P$ value \\
\hline Duration of anesthesia, hours & $5.00 \pm 1.19$ & $4.81 \pm 1.13$ & $5.18 \pm 1.22$ & 0.017 \\
\hline Dosage of fentanyl, $\mu \mathrm{g} / \mathrm{kg}$ & $24.9 \pm 6.1$ & $24.6 \pm 6.0$ & $25.2 \pm 6.1$ & 0.386 \\
\hline Dosage of etomidate, mg/kg & $0.23 \pm 0.08$ & $0.23 \pm 0.08$ & $0.23 \pm 0.08$ & 0.970 \\
\hline Use of anticholinergic drugs & 97 (39.9\%) & 49 (40.8\%) & 48 (39.0\%) & 0.773 \\
\hline Duration of surgery, hours & $4.00 \pm 1.16$ & $3.81 \pm 1.13$ & $4.18 \pm 1.16$ & 0.011 \\
\hline On-pump surgery & $114(46.9 \%)$ & $56(46.7 \%)$ & $58(47.2 \%)$ & 0.939 \\
\hline Coronary artery bypass grafts, number & $3.3 \pm 0.8$ & $3.2 \pm 0.8$ & $3.3 \pm 0.7$ & 0.365 \\
\hline Blood transfusion of at least $400 \mathrm{~mL}$ & $9(3.7 \%)$ & $1(0.8 \%)$ & $8(6.5 \%)$ & 0.036 \\
\hline APACHE $\|$ score ${ }^{a}$ & $6.43 \pm 3.25$ & $5.56 \pm 3.03$ & $7.28 \pm 3.24$ & $<0.001$ \\
\hline Serum cortisol concentration, $\mathrm{nmol} / \mathrm{L}$ & $549.9 \pm 300.2$ & $473.6 \pm 305.4$ & $625.6 \pm 275.9$ & $<0.001$ \\
\hline Serum cortisol level ${ }^{b}$ & & & & $<0.001$ \\
\hline Level 1 & $20(8.2 \%)$ & $12(10.0 \%)$ & $8(6.5 \%)$ & \\
\hline Level 2 & $145(59.7 \%)$ & $90(75.0 \%)$ & $55(44.7 \%)$ & \\
\hline Level 3 & $78(32.1 \%)$ & $18(15.0 \%)$ & $60(48.8 \%)$ & \\
\hline Duration of sedation, hours & $10.0(7.0-13.0)$ & $9.5(7.0-12.0)$ & $10.5(7.8-14.0)$ & 0.045 \\
\hline Use of benzodiazepines & $63(25.9 \%)$ & $28(23.3 \%)$ & 35 (28.5\%) & 0.362 \\
\hline Duration of mechanical ventilation, hours & $14.8(12.2-18.0)$ & $13.9(11.9-15.8)$ & $16.0(13.2-19.3)$ & $<0.001$ \\
\hline Postoperative LVEF, percentage ${ }^{c}$ & $54.8 \pm 8.7$ & $56.3 \pm 8.5$ & $53.4 \pm 8.7$ & 0.008 \\
\hline \multicolumn{5}{|l|}{ Postoperative complications } \\
\hline Cardiac insufficiency & $48(19.8 \%)$ & $16(13.3 \%)$ & $32(26.0 \%)$ & 0.013 \\
\hline Arrhythmia & $18(7.4 \%)$ & $5(4.2 \%)$ & $13(10.6 \%)$ & 0.057 \\
\hline Myocardial infarction & $1(0.4 \%)$ & $1(0.8 \%)$ & $0(0.0 \%)$ & 0.494 \\
\hline Respiratory insufficiency & $4(1.6 \%)$ & $0(0.0 \%)$ & $4(3.3 \%)$ & 0.122 \\
\hline Surgical bleeding & $5(2.1 \%)$ & $1(0.8 \%)$ & $4(3.3 \%)$ & 0.370 \\
\hline Sepsis & $5(2.1 \%)$ & $0(0.0 \%)$ & $5(4.1 \%)$ & 0.060 \\
\hline Pleural effusion & $13(5.3 \%)$ & $7(5.8 \%)$ & $6(4.9 \%)$ & 0.741 \\
\hline Stroke & $1(0.4 \%)$ & $0(0.0 \%)$ & $1(0.8 \%)$ & 1.000 \\
\hline Postoperative complications within 1 day $^{\mathrm{d}}$ & $67(27.6 \%)$ & $21(17.5 \%)$ & $46(37.4 \%)$ & 0.001 \\
\hline Postoperative complications within 5 days $^{\text {d }}$ & $82(33.7 \%)$ & $26(21.7 \%)$ & $56(45.5 \%)$ & $<0.001$ \\
\hline Postoperative complications within 28 days ${ }^{d}$ & $86(35.4 \%)$ & $28(23.3 \%)$ & $58(47.2 \%)$ & $<0.001$ \\
\hline
\end{tabular}

Data are presented as mean \pm standard deviation, number of patients (percentage), or median (interquartile range). ${ }^{\mathrm{a}} \mathrm{Scored}$ using worst values over the first 24

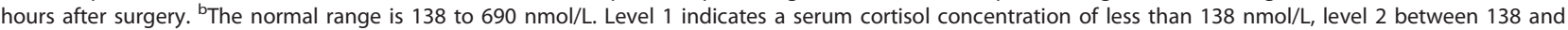
$690 \mathrm{nmol} / \mathrm{L}$, and level 3 of greater than $690 \mathrm{nmol} / \mathrm{L}$. 'Results of echocardiography (Simpson's method) performed before discharge from the hospital.

${ }^{\mathrm{d} C o m p l i c a t i o n s ~ t h a t ~ o c c u r r e d ~ b e f o r e ~ o r ~ d u r i n g ~ t h e ~ 1 s t, ~ 5 t h, ~ o r ~ 28 t h ~ p o s t o p e r a t i v e ~ d a y . ~ A P A C H E ~ I I, ~ A c u t e ~ P h y s i o l o g y ~ a n d ~ C h r o n i c ~ H e a l t h ~ E v a l u a t i o n ~ I I ; ~ L V E F, ~ l e f t ~}$ ventricular ejection fraction.

Preoperative psychiatric disorders, such as depression and cognitive impairment, are also strong predictors of postoperative delirium $[33,44]$. In the present study, only one patient who was previously diagnosed with schizophrenia and was taking antischizophrenic drugs at the time of surgery was excluded from the study for psychiatric reasons. This did not seem to produce patient selection bias.

It was reported that off-pump CABG surgery was associated with less frequent postoperative delirium [4]. However, this topic is controversial. Recent studies did not confirm that off-pump procedure or less cerebral emboli improved neurologic outcomes in patients undergoing CABG surgery $[45,46]$. Furthermore, it was found that systemic stress hormone response triggered by off-pump surgery was comparable with that after conventional on-pump surgery [47]. In the present study, there were no differences in the incidence of delirium $(58 / 114$ versus $65 / 129 ; P=0.939)$ and the serum cortisol concentration $(558.0 \pm 342.6 \mathrm{nmol} / \mathrm{L}$ versus $542.9 \pm 259.1 \mathrm{nmol} / \mathrm{L} ; P=0.702$ ) between patients undergoing on- or off-pump surgery. We therefore combined on- and off-pump surgeries and included the type of surgery in the analyses. The results showed no significant relationship between the type of surgery and the occurrence of postoperative delirium.

It has long been known that stress and high circulating glucocorticoid level can produce deterioration in neuropsychological function [19]. Studies showed that persistently elevated glucocorticoid levels may affect neurochemical transmission and lead to structural changes in hippocampal neurons [48]. Psychiatric symptoms are common 


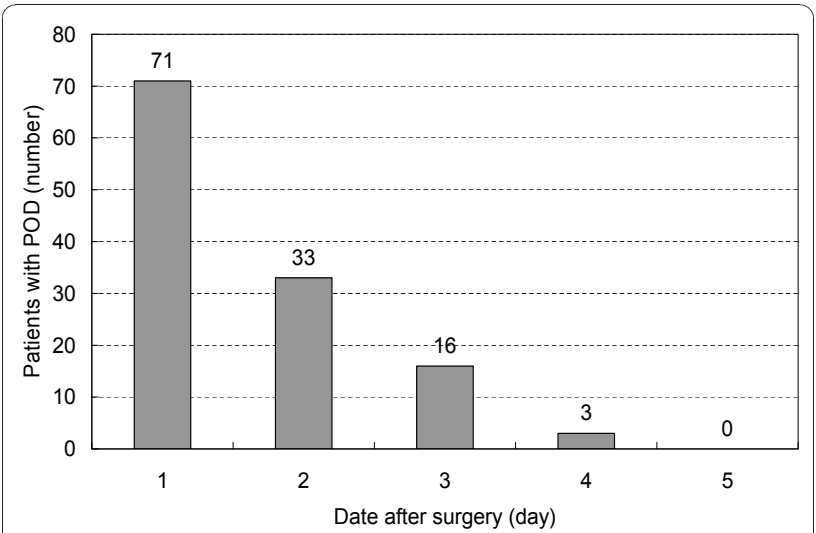

Figure 2 Number of patients whose first episode of delirious symptoms occurred during the postoperative period. Note that in $97.6 \%$ of the delirious cases (120 of 123), the initial symptom occurred within the first three days after surgery. POD, postoperative delirium.

adverse effects in patients undergoing systemic corticosteroid therapy [20]. For patients after acute ischemic stroke, high serum cortisol level was significantly correlated to the presence of acute confusional state [49]. In the preliminary study by McIntosh and colleagues [50], the occurrence of postoperative delirium was associated with a significant and unusually prolonged increase in circulating cortisol level. In a recent study, Shi and colleagues [23] found that high serum cortisol level was associated with increased incidence of postoperative delirium after noncardiac surgery.

We did not monitor the time-course changes of serum cortisol level in our study. In the ISPOCD2 (International Study of Postoperative Cognitive Dysfunction), salivary cortisol concentrations were monitored for a 3-month period. Peak levels were found in the morning of the first postoperative day [51]. For patients undergoing cardiac surgery, studies also found that serum cortisol concentrations peaked in the first postoperative day or from 4 to 12 hours after surgery and then recovered gradually toward baseline during several days [52,53]. In this study, we collected blood samples in the early morning of the first postoperative day in order to get a relatively high serum cortisol level. The normal range of morning serum cortisol concentration in our hospital laboratory is 138 to 690 $\mathrm{nmol} / \mathrm{L}$, which is broadly the same as that of other laboratories [54]. For the convenience of analyses, we divided the serum cortisol concentrations into three levels according to the normal range (that is, level 1 is lower than $138 \mathrm{nmol} / \mathrm{L}$, level 2 is within normal range, and level 3 is higher than $690 \mathrm{nmol} / \mathrm{L}$ ).

Our study demonstrated, for the first time, that elevated serum cortisol level is significantly correlated with

Table 4 Predictors of postoperative delirium.

\begin{tabular}{|c|c|c|c|}
\hline \multirow[t]{2}{*}{ Variable } & \multirow{2}{*}{$\begin{array}{c}\text { Univariate analyses }^{\mathrm{a}} \\
P \text { value }\end{array}$} & \multicolumn{2}{|c|}{ Multivariate logistic regression analysis ${ }^{\mathbf{b}}$} \\
\hline & & $\begin{array}{l}\text { Odds ratio } \\
(95 \% \mathrm{Cl})\end{array}$ & $P$ value \\
\hline Age, years & $<0.001$ & $1.111(1.065-1.159)$ & $<0.001$ \\
\hline History of diabetes mellitus & 0.035 & $1.905(1.001-3.622)$ & 0.049 \\
\hline Preoperative LVEF, percentage & 0.026 & - & - \\
\hline Preoperative NYHA functional class & 0.029 & - & - \\
\hline Preoperative EuroSCORE score & $<0.001$ & - & - \\
\hline Duration of surgery, hours & 0.013 & $1.360(1.010-1.831)$ & 0.043 \\
\hline Duration of anesthesia, hours ${ }^{c}$ & 0.020 & - & - \\
\hline Blood transfusion of at least $400 \mathrm{~mL}$ during surgery & 0.048 & - & - \\
\hline Postoperative APACHE I| score & $<0.001$ & - & - \\
\hline Serum cortisol concentration, $\mathrm{nmol} / \mathrm{L}^{\mathrm{C}}$ & $<0.001$ & - & - \\
\hline Serum cortisol level, every level increase ${ }^{d}$ & $<0.001$ & $3.091(1.763-5.418)$ & $<0.001$ \\
\hline Postoperative LVEF, percentage & 0.009 & - & - \\
\hline Postoperative cardiac insufficiency ${ }^{c}$ & 0.015 & & - \\
\hline Postoperative arrhythmia ${ }^{c}$ & 0.065 & - & - \\
\hline Postoperative complications within 1 day $^{e}$ & 0.001 & $2.485(1.184-5.214)$ & 0.016 \\
\hline Postoperative complications within 5 days ${ }^{c, e}$ & $<0.001$ & - & - \\
\hline Postoperative complications within 28 days ${ }^{c, e}$ & $<0.001$ & - & - \\
\hline
\end{tabular}

${ }^{\mathrm{a}}$ Occurrence of postoperative delirium was modeled as a function of a single predictor. ${ }^{\mathrm{b}}$ Occurrence of postoperative delirium was modeled as a function of all predictors that differed $(P<0.10)$ in the univariate analyses. Excluded were nine cases with missing values for at least one of the risk factors in the model. Multivariate logistic regression analysis was performed by using a forward (conditional) stepwise procedure. 'Variable was not included in the multiple logistic regression analysis. ${ }^{\mathrm{d}}$ The normal range is 138 to $690 \mathrm{nmol} / \mathrm{L}$. Level 1 indicates a serum cortisol concentration of less than $138 \mathrm{nmol} / \mathrm{L}$, level 2 between 138 and $690 \mathrm{nmol} / \mathrm{L}$, and level 3 of greater than $690 \mathrm{nmol} / \mathrm{L}$. ${ }^{e}$ Complications that occurred before or during the 1st, 5th, or 28th postoperative day. APACHE II, Acute Physiology and Chronic Health Evaluation II; Cl, confidence interval; EuroSCORE, European System for Cardiac Operative Risk Evaluation; LVEF, left ventricular ejection fraction; NYHA, New York Heart Association. 


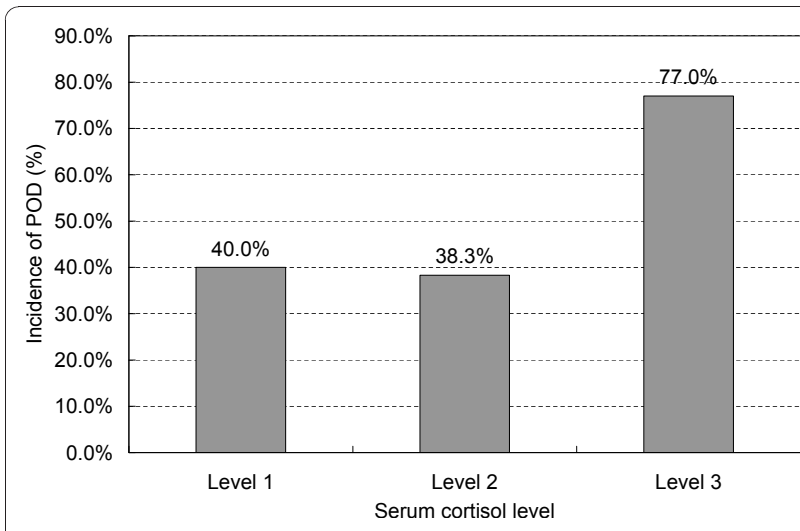

Figure 3 Relationship between serum cortisol level and incidence of postoperative delirium (POD) after coronary artery bypass graft surgery. Patients with a higher serum cortisol level had a significantly higher incidence of POD $(P<0.001)$. Level 1 indicates a serum cortisol concentration of less than $138 \mathrm{nmol} / \mathrm{L}$, level 2 indicates a serum cortisol concentration of between 138 and $690 \mathrm{nmol} / \mathrm{L}$, and level 3 indicates a serum cortisol concentration of greater than $690 \mathrm{nmol} / \mathrm{L}$

increased incidence of delirium in patients after cardiac surgery. In our results, the number of new delirious cases was highest on the first postoperative day and decreased rapidly across time, with $97.6 \%$ of the delirious cases occurring within the first three days after surgery. The median (interquartile range) duration of delirious symptoms was 2 ( 1 to 4 ) days. The time course of postoperative delirium is similar to the reported changes of serum cortisol level after cardiac surgery $[52,53]$. This accordance also indicates a relationship between serum cortisol level and occurrence of postoperative delirium.

It remains unknown whether hypercortisolemia is a cause or an effect of postoperative delirium. Studies found that an older population and patients with diabetes mellitus have an increased baseline cortisol level and an attenuated negative feedback mechanism that inhibits further secretion of cortisol and are more reactive to stressful stimuli [55-57]. In clinical settings, these two populations are prone to develop postoperative delirium [2-6,28-32,39,40]. An earlier study of delirium in patients with lower respiratory tract infection showed that older patients who were nonsuppressor on the dexamethasone suppression test were at increased risk for developing delirium during acute illness [58]. It is possible that abnormal hypothalamic-pituitary-adrenal function plays a basic role in the mechanism of delirium.

Surgery-related stress is not the only factor that contributes to the elevated cortisol level. In the present study, we did not find significant correlations between serum cortisol concentration and duration of surgery, use of cardiopulmonary bypass during surgery, or duration of mechanical ventilation in the ICU. Velissaris and colleagues [47] reported a similar cortisol response curve in patients undergoing on- and off-pump surgery. Other conditions (such as anxiety, depression, and cognitive impairment) are also related to higher serum cortisol concentration [55,59]. However, we did not perform screen tests for these conditions in this study. On the other hand, 20 patients $(8.2 \%)$ in our study had a serum cortisol concentration that was lower than normal in the morning of the first postoperative day. The possible reason is that etomidate was used for anesthesia induction in all patients. It has been found that a single dose of etomidate can cause adrenal inhibition for 12 to 24 hours [60]. However, this did not seem to produce significant adverse effects in our study since only one of these patients needed inotropic therapy for more than 24 hours and no glucocorticoid replacement therapy was administered in the ICU.

There are several limitations of this study. First, we did not perform baseline psychiatric and cognitive screening tests. It was reported that preoperative mental disorders (such as depression, cognitive impairment, and dementia) are strong predictors of postoperative delirium $[33,44]$. These factors are not included in the multivariate analysis in our study and thus may interfere with the final results. Second, serum cortisol concentrations were not measured at baseline. They were measured at only one time point after surgery. We were unable to determine whether patients with elevated baseline

Table 5 Outcomes of patients

\begin{tabular}{|c|c|c|c|}
\hline Variable & Non-delirious patients $(n=120)$ & Delirious patients $(n=123)$ & $P$ value \\
\hline Number of postoperative complications per patient & & & 0.001 \\
\hline 0 & $92(76.7 \%)$ & $65(52.8 \%)$ & \\
\hline 1 & $24(20.0 \%)$ & $51(41.5 \%)$ & \\
\hline 2 & $4(3.3 \%)$ & $6(4.9 \%)$ & \\
\hline$\geq 3$ & $0(0.0 \%)$ & $1(0.8 \%)$ & \\
\hline Duration of ICU stay, hours & $22.0(21.0-46.0)$ & $45.3(22.8-87.3)$ & $<0.001$ \\
\hline Duration of postoperative hospital stay, days & $7(7-7)$ & $7(7-10)$ & $<0.001$ \\
\hline Total costs of hospitalization, $\times 1,000 \mathrm{CNY}$ & $54.9(48.1-63.8)$ & $57.6(51.0-67.4)$ & 0.057 \\
\hline
\end{tabular}

Data are presented as number of patients (percentage) or median (interquartile range). CNY, Chinese Yuan; ICU, intensive care unit. 
serum cortisol level were more prone to develop postoperative delirium and whether the time course of postoperative delirium was exactly correlated with that of serum cortisol level. Third, we did not observe the long-term effects of surgery on postoperative cognitive dysfunction. Therefore, we could not, as Koster and colleagues [61] had, determine whether there is an association between postoperative delirium and long-term outcomes. Fourth, our study did not reveal the causal relationship between the elevated cortisol level and the occurrence of delirium. Hypercortisolemia may have a direct impact on delirious symptoms, but it is also possible that hypercortisolemia merely reflects the stress associated with delirium [62]. Therefore, further study is needed to illuminate the mechanisms by which circulating cortisol level may affect delirium.

\section{Conclusions}

The results of our study showed that delirium was a common complication after CABG surgery. High serum cortisol level was associated with increased risk of postoperative delirium. Patients who developed delirium had outcomes that were worse than those who did not.

\section{Key messages}

- Postoperative delirium was a common complication after coronary artery bypass graft surgery.

- High serum cortisol level was associated with increased risk of postoperative delirium. Whether this relationship is causal or due to other confounders is still unclear.

- Patients who developed delirium had outcomes that were worse than those who did not.

\begin{abstract}
Abbreviations
CABG: coronary artery bypass graft; CAM-ICU: Confusion Assessment Method for the Intensive Care Unit; Cl: confidence interval; DSM-IV: Diagnostic and Statistical Manual of Mental Disorders, Fourth Edition; ICU: intensive care unit; OR: odds ratio; RASS: Richmond Agitation Sedation Scale.
\end{abstract}

\section{Acknowledgements}

The authors gratefully acknowledge Xin-Yu Sun (Psychiatric Department, Peking University Sixth Hospital) for her psychiatric consultation and Sai-Nan Zhu (Department of Medical Statistics, Peking University First Hospital) for her help with the statistical analysis.

\section{Author details}

${ }^{1}$ Department of Anesthesiology and Surgical Intensive Care, Peking University First Hospital, No. 8 Xishiku Street, Beijing 100034, PR China. ¿Department of Anesthesiology, Cardiovascular Institute and Fuwai Hospital, Chinese Academy of Medical Sciences and Peking Union Medical College, No. 167 Beilishi Road, Beijing 100037, PR China.

\section{Authors' contributions}

D-LM assessed the occurrence of postoperative delirium, collected the patients' data, and drafted the manuscript. D-XW designed the study, performed the statistical analysis, and revised the manuscript and approved the final version to be published. L-HL, Q-JY, and C-XS participated in the study design and collected the patients' data. G-JS and JL performed the measurements and collected the patients' data. All authors read and approved the final manuscript.

\section{Competing interests}

The authors declare that they have no competing interests.

Received: 11 July 2010 Revised: 5 October 2010

Accepted: 30 December 2010 Published: 30 December 2010

\section{References}

1. American Psychiatric Association: Diagnostic and Statistical Manual of Mental Disorders, Fourth Edition (DSM-IV) Washington, DC: American Psychiatric Association; 1994

2. Sockalingam S, Parekh N, Bogoch II, Sun J, Mahtani R, Beach C, Bollegalla N, Turzanski S, Seto E, Kim J, Dulay P, Scarrow S, Bhalerao S: Delirium in the postoperative cardiac patient: a review. J Card Surg 2005, 20:560-567.

3. Norkiene I, Ringaitiene D, Misiuriene I, Samalavicius R, Bubulis R, Baublys A, Uzdavinys $\mathrm{G}$ : Incidence and precipitating factors of delirium after coronary artery bypass grafting. Scand CardiovasC J 2007, 41:180-185.

4. Bucerius J, Gummert JF, Borger MA, Walther T, Doll N, Falk V, Schmitt DV, Mohr FW: Predictors of delirium after cardiac surgery delirium: effect of beating-heart (off-pump) surgery. J Thorac Cardiovasc Surg 2004 127:57-64.

5. Chang YL, Tsai YF, Lin PJ, Chen MC, Liu CY: Prevalence and risk factors for postoperative delirium in a cardiovascular intensive care unit. Am J Crit Care 2008, 17:567-575.

6. Loponen P, Luther M, Wistbacka JO, Nissinen J, Sintonen $H$, Huhtala H, Tarkka MR: Postoperative delirium and health related quality of life after coronary artery bypass grafting. Scand Cardiovasc J 2008, 42:337-344.

7. Ely EW, Gautam S, Margolin R, Francis J, May L, Speroff T, Truman B, Dittus R, Bernard R, Inouye SK: The impact of delirium in the intensive care unit on hospital length of stay. Intensive Care Med 2001, 27:1892-1900.

8. Ely EW, Shintani A, Truman B, Speroff T, Gordon SM, Harrell FE Jr, Inouye SK, Bernard GR, Dittus RS: Delirium as a predictor of mortality in mechanically ventilated patients in the intensive care unit. JAMA 2004, 291:1753-1762.

9. Morandi A, Jackson JC, Ely EW: Delirium in the intensive care unit. Int Rev Psychiatry 2009, 21:43-58.

10. Milbrandt EB, Deppen $S$, Harrison PL, Shintani AK, Speroff $T$, Stiles RA, Truman B, Bernard GR, Dittus RS, Ely EW: Costs associated with delirium in mechanically ventilated patients. Crit Care Med 2004, 32:955-962

11. Lin SM, Liu CY, Wang CH, Lin HC, Huang CD, Huang PY, Fang YF, Shieh MH, Kuo HP: The impact of delirium on the survival of mechanically ventilated patients. Crit Care Med 2004, 32:2254-2259.

12. Inouye SK: Delirium in older persons. N Engl J Med 2006, 354:1157-1165.

13. Gunther ML, Morandi A, Ely EW: Pathophysiology of delirium in the intensive care unit. Crit Care Clin 2008, 24:45-65.

14. Schneider F, Böhner H, Habel U, Salloum JB, Stierstorfer A, Hummel TC, Miller C, Friedrichs R, Müller EE, Sandmann W: Risk factors for postoperative delirium in vascular surgery. Gen Hosp Psychiatry 2002, 24:28-34.

15. Marcantonio E, Ta T, Duthie E, Resnick NM: Delirium and psychomotor types: their relationships with outcomes after hip fracture repair. J Am Geriatr Soc 2002, 50:850-857.

16. Milstein A, Pollack A, Kleinman G, Barak Y: Confusion/delirium following cataract surgery: an incidence study of 1-year duration. Int Psychogeriatr 2002, 14:301-306.

17. Chernow B, Alexander HR, Smallridge RC, Thompson WR, Cook D, Beardsley D, Fink MP, Lake CR, Fletcher JR: Hormonal responses to graded surgical stress. Arch Intern Med 1987, 147:1273-1278.

18. Widmer IE, Puder JJ, König C, Pargger H, Zerkowski HR, Girard J, Müller B: Cortisol response in relation to the severity of stress and illness. $J$ Clin Endocrinol Metab 2005, 90:4579-4586.

19. Lupien SJ, Maheu F, Tu M, Fiocco A, Schramek TE: The effects of stress and stress hormones on human cognition: implications for the field of brain and cognition. Brain Cogn 2007, 65:209-237.

20. Warrington TP, Bostwick JM: Psychiatric adverse effects of corticosteroids. Mayo Clin Proc 2006, 81:1361-1367.

21. Chrousos GP, Kino T: Glucocorticoid action networks and complex psychiatric and/or somatic disorders. Stress 2007, 10:213-219. 
22. Belanoff JK, Gross K, Yager A, Schatzberg AF: Corticosteroids and cognition. J Psychiat Res 2001, 35:127-145.

23. Shi CM, Wang DX, Chen KS, Gu XE: Incidence and risk factors of delirium in critically ill patients after non-cardiac surgery. Chin Med J (Engl) 2010, 123:993-999.

24. Sessler CN, Gosnell MS, Grap MJ, Brophy GM, O'Neal PV, Keane KA, Tesoro EP, Elswick RK: The Richmond Agitation-Sedation Scale: validity and reliability in adult intensive care unit patients. Am J Respir Crit Care Med 2002, 166:1338-1344.

25. Ely EW, Truman B, Shintani A, Thomason JW, Wheeler AP, Gordon S, Francis J, Speroff T, Gautam S, Margolin R, Sessler CN, Dittus RS, Bernard GR: Monitoring sedation status over time in ICU patients: reliability and validity of the Richmond Agitation-Sedation Scale (RASS). JAMA 2003, 289:2983-2991.

26. Ely EW, Margolin R, Francis J, May L, Truman B, Dittus R, Speroff T, Gautam S, Bernard GR, Inouye SK: Evaluation of delirium in critically ill patients: validation of the Confusion Assessment Method for the Intensive Care Unit (CAM-ICU). Crit Care Med 2001, 29:1370-1379.

27. Ely EW, Inouye SK, Bernard GR, Gordon S, Francis J, May L, Truman B, Speroff T, Gautam S, Margolin R, Hart RP, Dittus R: Delirium in mechanically ventilated patients: validity and reliability of the confusion assessment method for the intensive care unit (CAM-ICU). JAMA 2001 286:2703-2710.

28. Rolfson DB, McElhaney JE, Rockwood K, Finnegan BA, Entwistle LM, Wong JF, Suarez-Almazor ME: Incidence and risk factors for delirium and other adverse outcomes in older adults after coronary artery bypass graft surgery. Can J Cardiol 1999, 15:771-776.

29. Eriksson M, Samuelsson E, Gustafson Y, Aberg T, Engström KG: Delirium after coronary bypass surgery evaluated by the organic brain syndrome protocol. Scand Cardiovasc J 2002, 36:250-255.

30. Santos FS, Velasco IT, Fráguas R Jr: Risk factors for delirium in the elderly after coronary artery bypass graft surgery. Int Psychogeriatr 2004, 16:175-193.

31. Rudolph JL, Babikian VL, Birjiniuk V, Crittenden MD, Treanor PR, Pochay VE, Khuri SF, Marcantonio ER: Atherosclerosis is associated with delirium after coronary artery bypass graft surgery. J Am Geriatr Soc 2005, 53:462-466.

32. Rudolph JL, Jones RN, Grande LJ, Milberg WP, King EG, Lipsitz LA, Levkoff SE, Marcantonio ER: Impaired executive function is associated with delirium after coronary artery bypass graft surgery. J Am Geriatr SOC 2006, 54:937-941.

33. Rudolph JL, Jones RN, Levkoff SE, Rockett C, Inouye SK, Sellke FW, Khuri SF, Lipsitz LA, Ramlawi B, Levitsky S, Marcantonio ER: Derivation and validation of a preoperative prediction rule for delirium after cardiac surgery. Circulation 2009, 119:229-236.

34. Ebert AD, Walzer TA, Huth C, Herrmann M: Early neurobehavioral disorders after cardiac surgery: a comparative analysis of coronary artery bypass graft surgery and valve replacement. J Cardiothorac Vasc Anesth 2001, 15:15-19.

35. Hudetz JA, lqbal Z, Gandhi SD, Patterson KM, Byrne AJ, Pagel PS: Postoperative delirium and short-term cognitive dysfunction occur more frequently in patients undergoing valve surgery with or without coronary artery bypass graft surgery compared with coronary artery bypass graft surgery alone: results of a pilot study. J Cardiothorac Vasc Anesth 2010.

36. Girard TD, Pandharipande PP, Ely EW: Delirium in the intensive care unit. Crit Care 2008, 12(Suppl 3):S3.

37. de Oliveira DC, Ferro CR, de Oliveira JB, Malta MM, Barros Neto P, Cano SJ, Martins SK, Souza LC, Jatene AD, Piegas LS: Risk factors for stroke after coronary artery bypass grafting. Arq Bras Cardiol 2008, 91:213-216, 234237.

38. Nötzold A, Michel K, Khattab AA, Sievers HH, Hüppe M: Diabetes mellitus increases adverse neurocognitive outcome after coronary artery bypass grafting surgery. Thorac Cardiovasc Surg 2006, 54:307-312.

39. Bucerius J, Gummert JF, Walther T, Doll N, Falk V, Onnasch JF, Barten MJ, Mohr FW: Impact of diabetes mellitus on cardiac surgery outcome. Thorac Cardiovasc Surg 2003, 51:11-16.

40. Bucerius J, Gummert JF, Walther T, Doll N, Barten MJ, Falk V, Mohr FW: Diabetes in patients undergoing coronary artery bypass grafting. Impact on perioperative outcome. Z Kardiol 2005, 94:575-582.

41. Weckbach S, Findeisen HM, Schoenberg SO, Kramer H, Stark R, Clevert DA, Reiser MF, Parhofer KG: Systemic cardiovascular complications in patients with long-standing diabetes mellitus: comprehensive assessment with whole-body magnetic resonance imaging/magnetic resonance angiography. Invest Radiol 2009, 44:242-250.

42. Krähenbühl ES, Immer FF, Stalder M, Englberger L, Eckstein FS, Carrel TP: Temporary neurological dysfunction after surgery of the thoracic aorta: a predictor of poor outcome and impaired quality of life. Eur $J$ Cardiothorac Surg 2008, 33:1025-1029.

43. Klugkist M, Sedemund-Adib B, Schmidtke C, Schmucker P, Sievers HH, Hüppe M: Confusion Assessment Method for the Intensive Care Unit (CAM-ICU): diagnosis of postoperative delirium in cardiac surgery [in German]. Anaesthesist 2008, 57:464-474.

44. Kazmierski J, Kowman M, Banach M, Fendler W, Okonski P, Banys A, Jaszewski R, Rysz J, Mikhailidis DP, Sobow T, Kloszewska I: Incidence and predictors of delirium after cardiac surgery: results from The IPDACS Study. J Psychosom Res 2010, 69:179-185.

45. Liu YH, Wang DX, Li LH, Wu XM, Shan GJ, Su Y, Li J, Yu QJ, Shi CX, Huang YN, Sun W: The effects of cardiopulmonary bypass on the number of cerebral microemboli and the incidence of cognitive dysfunction after coronary artery bypass graft surgery. Anesth Analg 2009, 109:1013-1022.

46. Rudolph $J$, Babikian VL, Treanor P, Pochay VE, Wigginton JB, Crittenden MD, Marcantonio ER: Microemboli are not associated with delirium after coronary artery bypass graft surgery. Perfusion 2009, 24:409-415.

47. Velissaris T, Tang AT, Murray M, Mehta RL, Wood PJ, Hett DA, Ohri SK: A prospective randomized study to evaluate stress response during beating-heart and conventional coronary revascularization. Ann Thorac Surg 2004, 78:506-512.

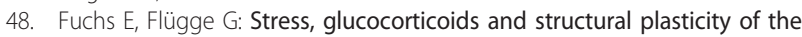
hippocampus. Neurosci Biobehav Rev 1998, 23:295-300.

49. Olsson T, Marklund N, Gustafson Y, Näsman B: Abnormalities at different levels of the hypothalamic-pituitary-adrenocortical axis early after stroke. Stroke 1992, 23:1573-1576.

50. Mclntosh TK, Bush HL, Yeston NS, Grasberger R, Palter M, Aun F, Egdahl RH: Beta-endorphin, cortisol and postoperative delirium: a preliminary report. Psychoneuroendocrinology 1985, 10:303-313.

51. Rasmussen LS, O'Brien JT, Silverstein JH, Johnson TW, Siersma VD, Canet J, Jolles J, Hanning CD, Kuipers HM, Abildstrom H, Papaioannou A, Raeder J, Yli-Hankala A, Sneyd JR, Munoz L, Moller JT: Is peri-operative cortisol secretion related to post-operative cognitive dysfunction? Acta Anaesthesiol Scand 2005, 49:1225-1231.

52. Roth-Isigkeit AK, Schmucker P: Postoperative dissociation of blood levels of cortisol and adrenocorticotropin after coronary artery bypass grafting surgery. Steroids 1997, 62:695-699.

53. Hoda MR, El-Achkar H, Schmitz E, Scheffold T, Vetter HO, De Simone R: Systemic stress hormone response in patients undergoing open heart surgery with or without cardiopulmonary bypass. Ann Thorac Surg 2006, 82:2179-2186.

54. Gunneberg A, Astley P, Goldie DJ: A survey of endocrine function testing by clinical biochemistry laboratories in the UK. Ann Clin Biochem 1999, 36(Pt 1):112.

55. Heffelfinger AK, Newcomer JW: Glucocorticoid effects on memory function over the human life span. Dev Psychopathol 2001, 13:491-513.

56. Chiodini I, Di Lembo S, Morelli V, Epaminonda P, Coletti F, Masserini B, Scillitani A, Arosio M, Adda G: Hypothalamic-pituitary-adrenal activity in type 2 diabetes mellitus: role of autonomic imbalance. Metabolism 2006, 55:1135-1140.

57. Chiodini I, Adda G, Scillitani A, Coletti F, Morelli V, Di Lembo S, Epaminonda P, Masserini B, Beck-Peccoz P, Orsi E, Ambrosi B, Arosio M: Cortisol secretion in patients with type 2 diabetes: relationship with chronic complications. Diabetes Care 2007, 30:83-88.

58. O'Keeffe ST, Devlin JG: Delirium and the dexamethasone suppression test in the elderly. Neuropsychobiology 1994, 30:153-156.

59. Lupien SJ, Nair NP, Brière S, Maheu F, Tu MT, Lemay M, McEwen BS, Meaney MJ: Increased cortisol levels and impaired cognition in human aging: implication for depression and dementia in later life. Rev Neurosci 1999, 10:117-139.

60. Vinclair M, Broux C, Faure P, Brun J, Genty C, Jacquot C, Chabre O, Payen JF: Duration of adrenal inhibition following a single dose of etomidate in critically ill patients. Intensive Care Med 2008, 34:714-719. 
61. Koster $\mathrm{S}$, Hensens $A G$, van der Palen J: The long-term cognitive and functional outcomes of postoperative delirium after cardiac surgery. Ann Thorac Surg 2009, 87:1469-1474.

62. Wolkowitz OM, Burke H, Epel ES, Reus VI: Glucocorticoids. Mood, memory, and mechanisms. Ann N Y Acad Sci 2009, 1179:19-40.

doi:10.1186/cc9393

Cite this article as: Mu et al:: High serum cortisol level is associated with increased risk of delirium after coronary artery bypass graft surgery: a prospective cohort study. Critical Care 2010 14:R238.

Submit your next manuscript to BioMed Central and take full advantage of:

- Convenient online submission

- Thorough peer review

- No space constraints or color figure charges

- Immediate publication on acceptance

- Inclusion in PubMed, CAS, Scopus and Google Scholar

- Research which is freely available for redistribution

Submit your manuscript at www.biomedcentral.com/submit
C Biomed Central 